Revue

Revue de l'histoire des religions

de Ihistoire des religions

$1 \mid 2011$

Varia

\title{
Vakirà Bara et baptême catholique. Un rituel inculturé à Madagascar
}

Vakirà Bara and Catholic Baptism. An Inculturated Ritual in Madagascar

Céline Réjasse

OpenEdition

Journals

Édition électronique

URL : http://journals.openedition.org/rhr/7715

DOI : 10.4000/rhr.7715

ISSN : 2105-2573

Éditeur

Armand Colin

Édition imprimée

Date de publication : 1 mars 2011

Pagination : 71-92

ISBN : 978-2200-92685-4

ISSN : 0035-1423

Référence électronique

Céline Réjasse, «Vakirà Bara et baptême catholique. Un rituel inculturé à Madagascar 》, Revue de I'histoire des religions [En ligne], 1 | 2011, mis en ligne le 01 mars 2014, consulté le 10 octobre 2020. URL : http://journals.openedition.org/rhr/7715 ; DOI : https://doi.org/10.4000/rhr.7715 


\section{Vakirà Bara et baptême catholique Un rituel inculturé à Madagascar}

Dernière née des pratiques évangélisatrices catholiques, l'inculturation a été élaborée au lendemain du Concile Vatican II pour répondre au besoin d'ouverture culturelle de l'Église. L'inculturation est avant tout une fusion, une syncrétisation " contrôlée », le fruit d'un mariage entre le catholicisme et les cultures. Sur le terrain, les prêtres sont les artisans de cette fusion culturelle. À Madagascar, dans la région Bara, l'un d'eux a inventé un rituel inculturé, compromis entre un rituel de fraternisation par le sang (vakirà) et le sacrement du baptême. L'analyse de cette analogie catéchétique est l'occasion de revenir sur un concept problématique des sciences humaines et de proposer une approche nouvelle du syncrétisme.

\section{Vakirà Bara and Catholic Baptism.} An Inculturated Ritual in Madagascar.

Inculturation, the most recent of Catholic evangelizing practices, was developed following the Second Vatican Council in response to the Church's need for cultural openness. Above all, inculturation is a fusion, a "controlled" syncretisation, offspring of a marriage between Catholicism and the cultures in question. In their missionary territories, priests are the architects of this cultural fusion. In Madagascar's Bara region, one of them invented an inculturated ritual which is a compromise between a rite of blood-brotherhood (vakirà) and the sacrament of baptism. The present analysis of this catechistic analogy provides the opportunity to re-examine a problematic concept in human sciences and to propose a new approach to syncretism. 
La compréhension et l'étude du concept de culture a toujours été - quoique l'on puisse en penser - au centre des préoccupations de l'Église catholique. Ce qui a été détruit par l'Église au cours de ses rencontres avec les cultures, l'a été de façon très réfléchie. Ce qui est aujourd'hui au contraire délibérément conservé ou récupéré dans ces cultures, l'est encore de façon très pensée. Bien avant les théorisations et conceptualisations des sciences humaines, les missionnaires manipulaient et utilisaient consciemment les phénomènes multiples liés aux processus d'acculturation ${ }^{1}$, d'interpénétrations des cultures et de syncrétisation des formes religieuses. Avec plus ou moins de succès en fonction du contexte historico-culturel dans lequel elle fut insérée, l'Église catholique a tenté de travailler sur les cultures, de comprendre et d'exploiter leur mode de fonctionnement, surtout à travers la façon dont elles peuvent ou non s'interpénétrer et intégrer la religion chrétienne. C'est en cela sans doute que les missionnaires peuvent apparaître comme les pères de l'anthropologie culturelle.

Poussée par l'objectif de l'évangélisation, l'Église, à travers la missiologie, pose la question de la possibilité de modifier de façon délibérée la pensée et la façon de penser des individus formatés par une autre culture. Autrement dit, le catholicisme pose la question de la malléabilité d'une culture, de la façon dont elle peut être remodelée en fonction de la volonté d'individus qui y sont acteurs. Indirectement, l'Église catholique remet en doute l'idée même d'un inconscient culturel qui travaillerait la culture de l'intérieur, indépendamment de toute volonté individuelle. Face à la dernièrenée des stratégies évangélisatrices mise au point par l'Église catho-

1. Nous pensons, entre autres, aux Pères jésuites Nobili et Ricci, qui furent les premiers à utiliser l'auto-acculturation comme une stratégie évangélisatrice. Jean Lacouture, Jésuites : une multibibliographie, t. I : Les Conquérants, Paris, Éditions du Seuil, 1991. Shenwen Li, «Adaptation et Innovations : les stratégies évangélisatrices des missionnaires jésuites français en Chine au XVII siècle », p. 19-36, in Gilles Routhier et Frédéric Laugrand (dir.), L'Espace missionnaire. Lieu d'innovations et de rencontres interculturelles, Paris, Karthala et Presses de l'université de Laval, 2002. Voir également Shenwen Li, Stratégies missionnaires des jésuites français en Nouvelle-France et en Chine au XVII siècle, Sainte-Foy, Presses de l'université de Laval, Paris, L'Harmattan (édition commerciale remaniée de la thèse de l'auteur soutenue au département d'histoire de l'université de Laval, Québec, 2001). 
lique au lendemain du Concile Vatican II, il semblerait que le changement culturel puisse être dirigé, organisé, prévu. C'est en tout cas ce que suppose le concept catholique pratico-théorique d' ' inculturation ».

\section{UNE ÉGLISE INCULTURÉE}

Néologisme introduit par le jésuite et missiologue belge Pierre Charles en $1953^{2}$, l' « inculturation » est au départ comprise dans le même sens anthropologique que le concept d' «enculturation », qui résume le processus selon lequel on acquiert sa propre culture. Le terme sera utilisé au départ pour caractériser les rapports entre la foi chrétienne et les cultures africaines. Il faudra attendre une quinzaine d'années pour que ce néologisme soit utilisé dans son sens théologique et sa signification actuelle et devienne ainsi un nouveau concept de la théologie catholique. Repris et promu à partir des années 1975 par le Père Pedro Arrupe, supérieur général des jésuites, qui en donne une définition dans l'ensemble de ses communications ${ }^{3}$, le terme sera ensuite repris et « officialisé » par le Pape Jean Paul II dans sa Lettre Apostolique Catechesi Tradendae en 1979. En extrayant la notion d'inculturation de son carcan jésuite, le Pape lui confère une portée universelle. Ce thème, devenu aujourd'hui le leitmotiv de l'Église missionnaire post-Vatican II, reste cependant propre aux catholiques, qui eux-mêmes ne sont pas unanimes ${ }^{4}$.

Quoi qu'il en soit, la culture reste le noyau central des conceptions et des pratiques liées à cette volonté d'inculturation. À travers le concept d'inculturation, le changement culturel devient un simple mécanisme soumis à l'intentionnalité et au contrôle des acteurs.

«[...] there is a tendency for a society to select from many possibilities those innovations that are most compatible with the rest

2. Pierre Charles, "Missiologie et acculturation», Nouvelle Revue théologique, $\mathrm{n}^{\circ} 75,1953$, p. 15-32.

3. Pedro Arrupe, sj, Écrits pour évangéliser, présentés par Jean-Yves Calvez, Paris, 1985.

4. Pour approfondir ces dissensions, voir par exemple Klauspeter Blaser (dir.), Repères pour la mission chrétienne. Cinq siècles de tradition missionnaire. Perspectives œecuméniques, Paris, 2000. 
of its culture, especially with the underlying premises, basic attitudes, and fundamental goals. The Church [...] not only proclaims its message but must at the same time direct the process of selection that necessarily goes on in the minds and hearts of the recipients of the message.

[...] the local church's obligation [is] to guide the process of selectivity, reinterpretation, and ramification ${ }^{5}$. "

L'inculturation, c'est avant tout la nécessité et la possibilité d'extraire l'Évangile de son carcan culturel d'origine, d'en faire un « objet » a-culturel et a-temporel, greffable sur n'importe quelle autre culture. L'Évangile devient ainsi universel, car traductible ${ }^{6}$ et réinterprétable à volonté. Cet évangile dépouillé, $n u$, devra ensuite être inculturé, c'est-à-dire ré-implanté dans une autre culture, rhabillé par le système culturel local pour devenir « un principe d'inspiration, à la fois norme et force d'unification, qui transforme et recrée cette culture, étant ainsi à l'origine d'une "nouvelle création"7 $\gg$.

Une métaphore chère à l'Église catholique fait de ce processus fusionnel un véritable acte de procréation. Pour les représentants de l'Église catholique, l'inculturation est en effet avant tout « l'incarnation de l'Évangile dans les cultures autochtones ${ }^{8} \gg$. L'incarnation peut en fait être comprise de deux façons. La première fait de l'incarnation le moment de la mise en chair de la parole divine dans le personnage de Jésus-Christ ${ }^{9}$. Le concept théologique nous renvoie aussi à la conception proprement dite, c'est-à-dire à la mise en chair de Jésus-Christ - qui incarne alors le Verbe - dans le corps physique de Marie, sa mère. C'est dans ce deuxième cas que l'analogie avec le processus d'inculturation devient féconde ${ }^{10}$. De ce fait,

5. Louis J. Luzbetak, Svd, The Church and Cultures. New Perspectives in Missiological Anthropology; American Society of Missiology Series, $\mathrm{n}^{\circ} 12$, New York, 1988, p. 372-373.

6. Sur ces questions, voir le travail de Lamin Sanneh, Translating the Message. The Missionary Impact on Culture; American Society of Missiology Series, $\mathrm{n}^{\circ}$ 13, New York, 1989.

7. Pedro Arrupe, sj, «Lettre aux Jésuites, 14 mai 1979 », présentés par Jean-Yves Calvez, Écrits pour évangéliser, Paris, 1985, p. 169.

8. S.S. Jean-Paul II, Encyclique Slavorum Apostoli, 1985. [www.vatican. va].

9. «Et le Verbe s'est fait chair ». $J n, 1.14$.

10. Nous reprenons ici des observations déjà formulées dans notre DEA, soutenu en 2003 à l'École pratique des hautes Études sous la direction de Mme Anne- 
le Verbe est ici incarné dans ce qui pourrait être défini comme un corps vierge ou une matrice vierge : le corps biologique de Marie. Cette virginité - au-delà de considérations physiques - pourrait plutôt évoquer une virginité spirituelle. Marie - ou la matrice - sont en attente de la révélation de la Parole Divine, ici confondue avec Jésus-Christ. L'analogie avec le concept d'inculturation semblera alors plus évidente. En effet, l'inculturation peut être comprise à son tour comme l'incarnation de l'Évangile ou de la Parole Divine dans un corps vierge, ici celui de la culture dont la matrice ou le noyau est encore vierge. Porteur de l'Évangile, le catholicisme serait alors implanté ou incarné dans cette matrice culturelle nouvelle. L'inculturation se veut alors à double sens : la transformation de la culture par l'Évangile et la transformation de l'Évangile par la culture. L'Homme, dans sa dimension individuelle et spirituelle reste l'objectif de l'Église catholique, mais il devra désormais être atteint à travers sa culture. Ainsi, « il importe d'évangéliser la personne individuelle, mais aussi le milieu concret de cette personne, c'est-à-dire sa culture ${ }^{11}$ ».

L'évangélisation se veut donc fusion. Ce que l'Église catholique cherche aujourd'hui à travers le processus d'inculturation, c'est en fait une syncrétisation orthodoxe du christianisme et des cultures, dirigée et contrôlée par l'Église qui ne « va pas détruire les cultures et les valeurs locales ${ }^{12} »$. Mais lorsque ces valeurs locales sont incompatibles avec le christianisme, que sont donc supposés faire les artisans locaux de ce processus de fusion?

Notons au passage l'influence qu'ont pu exercer les théories des anthropologues culturalistes américains sur la naissance de ce que David-J. Bosch a désigné comme un nouveau paradigme missiologique ${ }^{13}$. Quoi qu'il en soit, ce nouveau modèle d'évangélisation va très vite se mondialiser et les prêtres de chaque pays seront

Marie Losonczy. Le sujet est aussi abordé par un article de Paula Elizabeth Holmes, " "We are Native Catholics": Inculturation and the Tekakwitha Conference », in Studies in Religion, vol. 28, no 2, 1999.

11. Achiel Peelman, L'Inculturation. L'Église et les Cultures, Université Saint Paul, Ottawa, 1988, p. 10.

12. Joseph-M. Ndi-Okalla (éd.), Inculturation et Conversion. Africains et Européens face au Synode des Églises d'Afrique, Paris-Karthala, 1994, p. 31-32.

13. David-J. Bosch, Dynamique de la mission chrétienne. Histoire et avenir des modèles missionnaires, Haho, Karthala, Labor et Fides, Lomé, Paris, Genève, 1995. 
appelés à le mettre en œuvre. Or, le passage de la théorie à la pratique suppose avant toute chose d'avoir étudié en détail la culture réceptacle, pour déterminer la façon dont le christianisme pourra y être inculturé et quels sont les rituels « porteurs » qui permettront de véhiculer et de greffer le christianisme à l'intérieur de la culture.

À Madagascar, comme dans le reste du monde, de nombreux prêtres ont orienté leurs études au séminaire sur l'anthropologie et sur la recherche de compatibilités et d'analogies généralement entre un sacrement catholique et un rituel de la culture réceptacle. La culture étant comprise de façon holiste, chaque prêtre chargé de la pastorale s'attache à trouver l'ouverture, la fenêtre qui permettra de faire entrer l'Évangile dans une culture. Ces recherches s'inscrivent donc dans une même vision de l'inculturation comme dispositif pastoral permettant de faire du christianisme une continuité « logique» de la culture traditionnelle.

Ces recherches ont donné lieu à de nombreuses thèses et de nombreux mémoires dont les bibliothèques des séminaires malgaches regorgent. Dans certains cas, les découvertes analogiques de ces prêtres ont aussi donné lieu à l'invention de rituels "inculturés », qui ont pris ou pas dans la culture en question. Nous nous intéresserons désormais au cas de l'un de ces rituels inculturés. À notre connaissance, ce rituel n'a eu lieu qu'une seule fois, à Ambatolahy dans la région bara d'Horombe, à Madagascar, le 23 avril 2000. C'est dans cette population Bara, historiquement réfractaire au christianisme que le Père Colombi, un lazariste italien a essayé de marier un rituel de fraternisation du sang (vakirà) avec le sacrement du baptême. Cette association, nous le verrons, avait été suggérée avant lui par les différents synodes des évêques d'Afrique, avec lesquels les évêques malgaches sont regroupés. L'alliance entre le vakirà et le baptême sera ensuite développée par l'ancien évêque du diocèse d'Ihosy dans la région Bara, Monseigneur Jean-Guy Rakotondravahatra, dans son catéchisme pour le diocèse ${ }^{14}$.

14. Mgr Jean-Guy Rakotondravahatra, Izaho Mino. Ny lahatr'Andriamanitra Ray be fitiavana. Katesizy fandalinam-pinoana. Diosezin'Ihosy, Diocèse Ihosy, 1990. Notons que dès 1956, le prêtre africain Vincent Mulago proposait de rapprocher le rituel de fraternisation du sang chez les Bantu du Bushi de la communion eucharistique : Vincent Mulago, «Le Pacte du sang et la communion alimentaire, pierres d'attente de la communion eucharistique », in Des prêtres noirs s'interrogent, Paris, Le Cerf, 1956, p. 171-187. 
Cette tentative de syncrétisation n'a en fait pas pris, et les religieux que nous avons pu interroger les années suivantes au cours de nos recherches sur le terrain ont, semble-t-il, oublié cette cérémonie inédite à laquelle certains avaient pourtant participé. Le Père Colombi a quant à lui renoncé au sacerdoce quelques années plus tard et serait actuellement rentré en Italie. Seuls les témoignages oraux des Bara ayant assisté à cette cérémonie et le témoignage écrit du Père Pierre-Marie Jérôme Ralahizafy ${ }^{15}$ nous permettent de dire que cette création originale n'est pas restée une invention virtuelle. Nous nous fondons sur ces témoignages pour essayer de comprendre comment cette alliance rituelle a été construite dans un premier temps, mais aussi pourquoi, dans un deuxième temps, ce rituel n'a pas été repris et diffusé.

\section{DÉroulement du VAKIRÀ}

Rituel de fraternisation ou d'alliance par le sang, comme il en existe dans le monde entier, le vakirà des Bara est une variante locale du fatidrà que l'on retrouve dans toutes les régions de Madagascar. Littéralement, le mot vakirà indique d'abord l'«incision » ou la " coupure sanglante », puisque la racine rà signifie « sang » tandis que la racine vaky, radical du verbe mamaky veut dire « casser, couper, inciser ». Le terme vakirà désigne à la fois l'acte rituel du pacte du sang, son résultat, mais aussi toutes les personnes impliquées par le serment, ou encore leur état d'êtres alliés. Un même mot désigne donc tout à la fois une cérémonie, les personnes qui y prennent part et leur état au sortir de la cérémonie. Ce phénomène linguistique est très fréquent dans la culture bara, puisque ce même

15. P. Pierre Marie Jérôme Ralahizafy, c.m., D'une Alliance culturelle à l'Alliance chrétienne : le vakirà bara et le sacrement du baptême. Mémoire de maîtrise en théologie correspondant à la licence canonique de théologie, sous la direction de l'Abbé Jean-Marie Aubert, Institut Catholique de Madagascar, Ambatoroka-Antananarivo. 2000, 157 p. Nous nous permettons de noter au passage que la soutenance de ce mémoire a eu lieu seulement quelques mois après la cérémonie en question. Notre sentiment est que les recherches préliminaires du Père Ralahizafy, lazariste, ont servi de base à l'invention et à la réalisation de ce rituel par le Père Colombi, lazariste lui aussi. Ces pratiques sont, au sein d'une même congrégation, tout à fait normales et même souhaitées, le travail de chacun devant servir un même objectif : ici, la conversion des Bara au catholicisme. 
principe se retrouve aussi par exemple dans le rituel de guérison bilo. Là encore, bilo désigne - entre autres - le malade, son état et le rituel de guérison qui permettra de le guérir. Mais revenons au rituel de fraternisation par le sang. Selon les régions et les différents clans bara, le vakirà pourra aussi être nommé atihéna, troky, ou filongoà a-pihàratsy. Notons au passage que troky sert aussi à désigner le « ventre, le siège des sentiments, des désirs $»^{16}$. En fait, le terme troky est utilisé plutôt pour désigner une parenté par plaisanterie, une alliance élargie entre villages voisins, ou entre les habitants d'un même village pour éviter les vols de bœufs, les razzias. Pour les Bara en effet, celui qui ne fait pas partie de la famille, même s'il habite la maison d'à côté est considéré comme un fahavalo, littéralement "le huitième ", le chiffre huit symbolisant pour les Bara l'ennemi, celui que l'on doit craindre. Celui qui ne fait pas partie de la parenté est donc toujours considéré comme un ennemi potentiel, d'où l'intérêt d'établir de multiples alliances offrant la possibilité d'étendre la parenté à un véritable réseau de sociabilités et permettant de rappeler que les hommes sont tous nés d'un même « ventre» $(\text { troky })^{17}$. Faire un troky, c'est rétablir le lien originel de parenté entre les hommes.

Ce type d'alliance s'insère à Madagascar dans la recherche plus générale du fihavanana, valeur philosophique primordiale pour tous les Malgaches, qui se comprend comme un lien d'amitié, d'amour, de parenté élargie entre tous les êtres, une philosophie du « vivre ensemble $\gg$ comme une seule grande famille ${ }^{18}$ avec toutes les obligations que cela comprend. Cette valeur qui unit tous les Malgaches est

16. P. Luigi Elli, c.m., Dictionnaire Bara - Français (Centre Sud de Madagascar), Ronéotypé, Tolagnaro, 1999, p. 496, inédit. À la suite du décès du Père Elli en 2001, ce dictionnaire a été transféré, avec le reste du «Fonds Elli » à la bibliothèque du Scolasticat Lazariste d'Antanantsoa. Fianarantsoa. Ce fonds réunit à la fois ses différents travaux, interviews, photos, diapositives et des centaines d'archives encore non classées en 2006. Voir aussi Luigi Elli, Dizionario bara-italiano, Éd. Ambozontany, Fianarantsoa, 1988.

17. "Niteraky raha mana ay maro be Ratany, pilonga tatroky raiky aby ndre ia ndre ino. » « La Terre a engendré de nombreux êtres vivants, ils sont tous parents issus d'un même ventre (sein), hommes et choses ", proverbe bara (traduction libre).

18. "Ny vakirà dia fihavanana amin'ireo tsy mifankalala [...] ny antone dia ny hampilongo ireo izay tsy milongo ». "Le vakirà a pour but de lier par le fihavanana tous ceux qui n'ont pas de relation de parenté [...] le but du vakirà est de créer une nouvelle relation d'amitié », témoignage de M. Rabernard, recueilli par nos soins à Ihosy le 13 mai 2004 (traduction libre). 
largement utilisée par l'Église catholique comme ciment de l'unité fraternelle des catholiques dans le monde. Pour l'Église catholique, le Fihavanana malgache est une de ces «pierres d'attentes» de l'Évangile ${ }^{19}$.

Au-delà de ce grand idéal commun, le rituel de fraternisation par le sang peut avoir chez les Bara d'autres buts beaucoup plus matérialistes et répondre à un idéal qui n'est pas seulement social, mais aussi économique ou politique. L'alliance permettra d'éviter par exemple les conflits entre les femmes rivales d'un mari polygame ou encore de créer entre deux hommes qui se volaient mutuellement des bœufs une solidarité nouvelle passant par la mise en commun du cheptel bovin. D'où l'intérêt de s'allier avec de grands dahalo ou voleurs de zébus réputés et riches en bœufs. L'avantage de chacun est donc de s'unir avec une personne plus influente socialement et économiquement, sans que soit exclue pour autant la possibilité de s'allier par amitié, affection ou encore pour intégrer un nouvel habitant dans le village ${ }^{20}$. Par ailleurs, notons que le pacte de sang n'est pas exclusif. Il peut être réalisé entre deux hommes, deux femmes ou entre un homme et une femme - qui devront donc se comporter comme frère et sœur -, un Bara et un non Bara.

Quoi qu'il en soit, cette parenté culturelle devient souvent supérieure à la parenté naturelle, puisqu'elle a été consacrée par le Fondateur ${ }^{21}$ (Zanahary), invoqué pendant le serment. En outre, le pacte

19. Sur cette question, voir le travail ethno-théologique du Frère des Écoles chrétiennes, Hilaire Aurélien-Marie Raharilalao : Église et Fihavanana à Madagascar, une herméneutique malgache de la Réconciliation chrétienne selon Saint Paul 2 Co 5, 17-21, thèse de doctorat présentée à l'Institut catholique de l'Afrique de l'Ouest (ICAO), Abidjan, Éditions Ambozontany, Fianarantsoa. 1991.

20. De nombreux colons profitèrent du vakirà pour s'allier à des chefs bara, et obtenir ainsi des esclaves et des bœufs, la plupart du temps en échanges d'armes. « Je connais un chef, Jadranaka, qui possède actuellement environ deux mille esclaves, et lorsque je fus devenu son frère de sang, il me fit présent de cinquante jeunes filles et garçons avec cent bœufs, qui, à l'heure actuelle, m'attendent et s'accroissent ", colonel Du Vergé, Madagascar et Peuplades indépendantes abandonnées par la France, Paris, 1887, p. 66. Voir aussi p. 70.

21. Contrairement aux catholiques qui utilisèrent le mot zanahary pour traduire l'idée du Dieu chrétien, monothéiste, et à de nombreux chercheurs qui font de zanahary un synonyme de Créateur, nous utiliserons le terme zanahary dans le sens que les Bara lui donnent, c'est-à-dire celui de procréateur primordial. Pour les Bara, nous semble-t-il, zanahary n'est pas seulement un Être Suprême ou un Créateur, mais il est avant tout l'Ancêtre primordial fondateur de la société bara. Zanahary est en premier lieu le créateur du groupe ou du lignage filongoany. Cela explique pourquoi lors de cérémonies ou demandes de bénédiction regroupant 
de sang entre deux individus implique aussi indirectement les autres parents et alliés, qui seront victimes des sanctions en cas de rupture du serment ou de trahison du pacte. Nous y reviendrons un peu plus loin.

Il convient à présent de donner une description ethnographique du rituel du vakirà.

\section{La préparation}

Lorsque deux individus veulent se lier par le vakirà, ils doivent avant tout prévenir leurs familles respectives, faire les présentations respectives en suivant les fomba, les manières de faire établies par les ancêtres. Ce moment des présentations est essentiel puisqu'il est l'occasion d'une déclinaison généalogique permettant de vérifier que les deux candidats au pacte de sang ne sont pas des parents biologiques éloignés et ignorés, et qu'ils ne vont pas s'engager inutilement dans un serment. Ce n'est qu'en l'absence d'une origine ancestrale commune que les deux candidats obtiendront l'accord respectif de leurs familles. Les futurs frères de sang vont ensuite chercher un officiant, le mpititika ou mpitsitsika, celui qui connaît la coutume et qui est capable de mener le rite à son terme. Il est aussi mpanompa, celui qui prononce les formules imprécatoires et les malédictions en cas de trahison du serment. C'est l'officiant qui présidera la cérémonie et sera le témoin du serment prononcé. C'est lui encore qui va décider du jour de la cérémonie et organiser la préparation du rituel et du matériel qui sera utilisé. En outre, la cérémonie demande un certain nombre de spectateurs qui pourront témoigner tout au long de leur vie du pacte qu'ont conclu les deux frères de sang. Il est donc indispensable d'inviter des témoins pour chaque candidat et d'attendre leur arrivée pour pouvoir faire le vakirà. La

plusieurs lignages, zanahary est invoqué au pluriel (nareo zanahary). Zanahary est en fait plutôt pour les Bara confondu avec les Razana Be, les ancêtres fondateurs. L'idée que les Bara ont toujours eu un seul Dieu et que zanahary est ce dieu monothéiste est une représentation déformée, héritée de la théorie des "pierres d'attentes » du catholicisme et des premiers missionnaires présents à Madagascar. Sur ces questions, nous renvoyons à la lecture de Pietro Lupo, Dieu dans la tradition malgache. Approches comparées avec les religions africaines et le christianisme, Paris - Fianarantsoa, Karthala - Éditions Ambozontany. 2006. Voir plus précisément sur le sujet les chapitres 2 et 3, p. 25-82. 
phase préparatoire au rituel proprement dit peut donc prendre un certain temps.

\section{Le serment}

Pour plus de clarté dans la description, nous renommerons les deux postulants au rituel de fraternisation. Le postulant « demandeur » du pacte, considéré comme l'aîné dans la fraternisation sera le «baptisé » $($ Razoky), tandis que le postulant « répondant» à la demande de pacte, considéré comme le cadet, sera quant à lui appelé Razandry ${ }^{22}$.

Généralement, la cérémonie a lieu dans la maison de celui qui a proposé l'alliance, ici, Razoky. En réalité, le lieu de la cérémonie dépend de l'endroit où se trouvent les protagonistes. Lorsque tout le monde est réuni, l'officiant demande une cuvette qu'il va placer au centre de la pièce. Il la remplit d'eau, y ajoute de la terre ramassée aux quatre points cardinaux autour du foyer, des grains de sel et de la suie. Il prend ensuite un tison qui brûle encore et l'éteint en le trempant dans la cuvette puis le laisse à l'intérieur ${ }^{23}$. Il s'adresse

22. Voir aussi les descriptions de ce rituel chez les auteurs suivants : Le Barbier, « Notes sur le pays des Bara-Imamono (Région d'Ankazoabo)» Bulletin de l'Académie Malgache, Nouvelle Série, Tome III. Imprimerie Franco-malgache, Tananarive, 1922. Jacques Faublee, La Cohésion des Sociétés Bara, Paris, PUF, 1954, notamment p. 108-111. P. Luigi Elli, Fomba Bara, Fianarantsoa, Imprimerie Saint-Paul 1999, p. 114-117 et 207-209.

23. Tous ces éléments ont une forte symbolique chez les Bara. L'Eau, Rano, est associée à l'idée de création, de fécondité et de purification. Elle est en général bénéfique et est utilisée lors des Tsipy Rano ou bénédictions. Dans ce cas, on utilisera de l'eau "vivante ", rano velo, ou eau de source. Mais l'eau est aussi indonptable et peut aussi entraîner la mort. - La Terre, Tany, est ici une terre prise au pied du foyer, donc mélangée de cendres. La terre est présente à tous les points cardinaux et représente à la fois l'espace de vie, mais aussi la condition de la vie de l'être humain. La Terre est sacrée (Tany masina) mais aussi impure, dans le sens où elle contient la putréfaction des cadavres. - Le Sel, Sira, se dissout dans l'eau, il meurt dans l'eau. On rappelle ainsi la malédiction Hanjary sira, hanjary talio (qu'il devienne du sel, qu'il devienne un tourbillon). Mais le sel dans l'eau peut aussi évoquer la mer et indirectement les ancêtres fondateurs, qui, selon la tradition orale, seraient venus par la mer. On peut voir alors dans l'utilisation du sel une façon de rappeler indirectement que les fondateurs sont les témoins du serment. - La Suie évoque quant à elle un foyer " stable ", dont le feu ne s'est pas éteint. Elle évoque aussi la possibilité de basculer dans la folie, le danger potentiel pour le traitre. - Le Tison éteint symbolise la mort possible de l'amitié entre les deux frères. Le tison chaud représente la chaleur, la vie. Trempé dans l'eau, la vie meurt en un instant. 
alors à Razoky et Razandry et leur demande s'ils sont prêts. En feignant de ne s'adresser qu'aux témoins, l'officiant met les deux postulants en garde contre la difficulté et la responsabilité qu'implique le serment qu'ils vont établir.

Razoky et Razandry, face à face, s'approchent de la cuvette. L'officiant, posté entre eux, à l'Ouest, prend une sagaie ${ }^{24}$ et l'enfonce dans le tison éteint. Il enroule un brin de jonc vinda autour du manche de la sagaie et demande aux deux postulants de tenir chacun avec la main droite le manche de la sagaie avec la tige de jonc. Razoky, l'aîné, doit placer sa main au-dessus de celle de Razandry. L'officiant, à l'aide d'une cuillère, prend un peu d'eau dans la cuvette et la verse sur leurs mains en invoquant les fondateurs (Mangaiky anareo Zanahary) en leur demandant de surveiller les deux futurs frères de sang pour qu'ils ne se trahissent pas et de veiller à leurs solidarité et assistance réciproque. Un certain nombre de malédictions ${ }^{25}$ sont aussi prononcées pour punir une éventuelle trahison ou un parjure.

En tenant toujours la sagaie de la main droite, Razoky, l'aîné, prend le couteau pendant que Razandry tient au-dessous une cuillère remplie avec le liquide pris dans la cuvette pour recevoir le sang de son aîné. Il s'incise l'épigastre ${ }^{26}$, puis il pose le bout du couteau ensanglanté dans la cuillère d'eau en comptant une première fois jusqu'à sept, prêtant serment entre chaque chiffre, puis une deuxième fois jusqu'à six, en formulant des souhaits de bonheur, et

24. La Sagaie est non seulement une arme, mais selon le Père Pierre Marie Jérôme Ralahizafy, elle est, comme le hazomanga, le lien entre le ciel et la terre, le monde visible et invisible, les ancêtres et les vivants. La sagaie crée donc, nous semble-t-il, un double lien vertical et un double lien horizontal. Double lien vertical entre chaque participant et ses ancêtres d'une part et double lien horizontal qui unit non seulement les deux participants, mais aussi à travers eux leurs ancêtres.

25. La formule courante est "maty fito ka mieñy, folo ka manjerizery», «sept doivent trépasser, jusqu'à dix plus ou moins assez». La formule permet ainsi de rappeler que toute la famille est impliquée et qu'un non-respect du pacte entraîne une possibilité de malédiction ou de vengeance sur sa propre famille. Ainsi, lorsqu'un frère de sang manque à son devoir d'assistance envers son vakirà, on dit que « le ventre est déchiré » (rivatsy ñy troky). On doit alors « recoudre le ventre » (mila hotribehy) par le sacrifice d'un bœuf offert par le traître.

26. Dans le cas d'un pacte de sang entre femmes, l'incision sera faite sur le bras. L'épigastre, qui correspond au sein chez les femmes est associé à l'allaitement et à la fécondité. Une coupure à cet endroit serait un risque de stérilité. C'est aussi une question de pudeur face aux nombreux hommes qui assistent à la cérémonie. 
se tait ${ }^{27}$. Razandry boit alors le sang mélangé à l'eau dans la cuillère, puis on inverse les rôles.

Après l'échange de serments, on remet la sagaie à sa place habituelle dans la maison et on enlève le morceau de jonc que l'on avait enroulé autour du manche. Les deux nouveaux frères doivent se glisser vers le côté est de la maison en restant face à face et en se regardant. Ils se déplacent en position assise et doivent en même temps soulever la cuvette et la faire tourner sur elle-même. Ils vident la cuvette dans le coin est de la maison ${ }^{28}$. Ils reprennent alors le jonc en le tenant chacun par un bout. Toujours face à face, ils enroulent chacun le jonc jusqu'à se rejoindre en son milieu. Razandry, le cadet, prend le jonc et le suspend au-dessous du toit avec le tison éteint. Brûler une nouvelle fois ce tison serait un danger pour les deux frères de sang. Razandry va ensuite chercher trois bouteilles de rhum qu'il avait suspendues à son arrivée dans un sac au mur sud de la maison. L'assistance boit et fait la fête pour sceller le pacte. Lorsque les gens rentrent chez eux, les deux frères de sang restent ensemble et dorment côte à côte. Avant de se séparer le lendemain, chacun décline à l'autre sa généalogie, son origine, ses alliés. Ils s'échangent leurs vêtements et à nouveau des promesses d'entraide mutuelle et d'amitié.

Une semaine plus tard, Razandry enlève le tison du toit de la maison et l'emmène au loin pour l'enterrer dans une fourmilière. Les deux frères se rencontrent ensuite pour se rendre leurs vêtements respectifs et reprennent leurs vies respectives en attendant que l'un des deux frères vienne voir l'autre en faisant appel au serment qu'ils ont passé pour lui demander son aide ou son soutien.

Voyons désormais sur quels fondements repose l'analogie établie par les catholiques entre le vakirà bara et le baptême catholique.

27. Dans la symbolique des nombres chez les Bara, le chiffre 7, Fito ou Feno, est l'accomplissement. Un nouveau-né sera déclaré accompli, parfait, quand toutes ses facultés de sens, représentées par le chiffre 7, auront été vérifiées. Ainsi, s'il possède bien deux oreilles, deux narines, une bouche et deux yeux, l'enfant est considéré comme «normal », « complet ». Sept est le signe du sort bénéfique. Le chiffre 6, Eni en bara, est le chiffre du soulagement, de la gratitude, de la plénitude. Heniky veut dire « plein », dans le sens de la gratitude (on pourrait le rapprocher du plerum latin. C'est un souhait de bénédiction comme par exemple (h)enin-kaveloma.

28. Dans la version rapportée par Jacques Faublee, ce travail est effectué par les témoins du serment. Op. cit. p. 110. 


\section{LE BAPTÊME COMME ALLIANCE}

Répondant à la volonté d'aggiornamento voulu par l'Église catholique lors du deuxième Concile de Vatican, et aux nouvelles directives en matière d'inculturation, l'ancien évêque d'Ihosy, Mgr Jean-Guy Rakotondravahatra a créé un catéchisme pour son diocèse en se référant au rituel romain et à la Liturgie officielle de l'Église. Ce catéchisme, adapté à la spécificité de la région bara, répond aux exigences fixées lors du concile qui précise, dans la Constitution sur la Sainte Liturgie :

« [...] en suivant la nouvelle édition du rituel romain, des rituels particuliers, adaptés aux nécessités de chaque région, y compris en ce qui concerne la langue, seront préparés au plus tôt par l'autorité ecclésiastique qui a compétence sur le territoire, mentionnée à l'article 22 $\S 2$ de la présente Constitution; et, une fois les actes révisés par le Siège apostolique, ces rituels seront employés dans leurs régions respectives $^{29}$. »

Chacun des sept sacrements de l'Église catholique est abordé dans ce catéchisme dont le but est avant tout de servir les catéchistes locaux et de les orienter dans la préparation des candidats aux sacrements. Sept leçons sont consacrées au baptême dans le livre Izaho Mino ny lahatr'Andriamanitra Ray be fitiavana ${ }^{30}$, catéchisme en question. Ces sept leçons couvrent une totalité de 44 pages. C'est au cours de la troisième leçon que l'analogie catéchétique entre baptême et vakirà apparaît. L'analogie est essentiellement basée sur la notion d'« alliance ». Tout au long de ces sept leçons, le baptême est abordé comme une alliance entre l'homme et Dieu.

« Dans le baptême, nous sommes avec Dieu comme dans le vakirà. Faire un vakirà est un acte volontaire, jamais forcé. En outre, il est interdit de trahir les paroles (promesses) prononcées pendant le serment pour être frères et amis dans le vakirä ${ }^{31}$.»

29. Constitution sur la Sainte Liturgie, 63b; in Concile ocuménique Vatican II. Constitutions, Décrets, Déclarations, Messages, Paris, Éditions du Centurion, 1989 (1967), p. 178.

30. «Je crois au destin de Dieu le Père plein d'amour». Traduction libre. Op. cit.

31. «Tahatahaka ny olona mifanao velirano na fato-drà na vakirà isika sy Zanahary amin'ny Batemy. An-tsitrapo no anaovana ny velirano na fato-drà, fa tsy an-terivozona. Ary fady mihitsy ny mivadika amin'ny teny omena amin'ny velirano, na ny filongoana sy fanekem-pihavanana amin'ny fato-drà », traduction libre. Mgr Jean-Guy Rakotondravahatra, op. cit. p. 165 
Le baptême, tout comme le vakirà, doit être un acte volontaire, librement décidé. Mais, une fois établi, le serment ne pourra plus être rompu. Pour un Bara, l'analogie avec le vakirà pourra alors faire craindre un système de malédiction-sanction contradictoire avec l'idée catholique du pardon. Par ailleurs, l'analogie laisse entendre que le baptisé, à travers le rituel du baptême, devient " frère cadet » de Jésus-Christ et entre ainsi dans sa grande famille, celle de la « Sainte Trinité ».

«Par le baptême, non seulement nous devenons frères cadets de Jésus-Christ mais aussi enfants de Dieu : nous aurons aussi le même héritage que Christ dans Dieu, héritiers de Dieu Notre Père. [...]. En faisant le baptême au nom du Père, du Fils et du Saint Esprit, nous signifions que nous entrons dans un seul Peuple avec Dieu. Cette union ne dépend pas de la volonté des hommes, mais vient de l'amour de $\mathrm{Dieu}^{32} .{ }^{\prime}$

«Les baptisés sont comme des frères et sœurs biologiques dans une même famille, ils forment aussi une seule et même famille dans l'Église. Les baptisés sont comme une fratrie, mais dans le baptême on ne reçoit qu'une seule vie, celle de Jésus-Christ ressuscité. Les baptisés forment une seule et même famille où chacun est un enfant adopté par $\mathrm{Dieu}^{33} . »$

Le catéchisme propose une lecture et une explication du baptême en s'appuyant sur le rituel du vakirà. Ainsi, en s'alliant avec JésusChrist et en devenant frère de sang de celui-ci, l'homme devient le fils adoptif de Dieu et entre dans la grande famille unique du Père, du Fils et du Saint Esprit. La majorité des Bara demandant le baptême sont des adultes qui pour la plupart ont déjà tous réalisé un vakirà. Sachant que pour les Bara, l'alliance ou fraternisation par le sang a souvent un intérêt politico-économique, et que, pour eux, un enfant adopté devient un héritier au même titre que les enfants naturels, comment le baptême expliqué en ces termes peut-il être

32. «Amin'ny Batemy isika no tonga zandrin'I Kristy, fa tonga zanak'Andriamanitra: koa mpiray lova amin'i Kristy àry isika, mpandova an'i Zanahary raintsika tahaka Azy. [...]. Amin'ny anaran'ny Ray sy ny Zanaka sy ny Fanahy Masina no anaovana Batemy ny olona, mba hilazana fa tonga foko iraika Aminy isika, ka tsy asan'olombelona izany fa vokatry ny fitiavan'Andriamanitra antsika fotsiny ihany. »

33. "Toy ny maha-fianakaviana iray ny mpiray tampo no maha-fianakaviana iray ny vita Batemy rehetra ao amin'ny Fiangonana: "Tampo iraika" ny vita Batemy, fa Aina iray ihany no raisiny amin'ny Batemy, dia ny Ain' $i$ Kristy tafatsangan-ko velona. Ary fianakaviana iray ihany izy, fa samy zanaka natsangan'Andriamanitra », ibid., p. 180. 
interprété par eux? Nous verrons plus loin que la réponse est loin d'être évidente. Mais revenons maintenant à l'analogie catéchétique explorée par l'évêque d'Ihosy et voyons ce qui a été proposé en matière de ritualisation proprement dite.

\section{UN RITUEL INCULTURÉ}

Le catéchisme ne se contente pas de proposer une analogie entre le vakirà et le baptême pour permettre aux Bara de mieux comprendre le sacrement, il propose aussi un modèle de ritualisation du sacrement inculturé ${ }^{34}$.

« Serment ou Pacte de sang: Cet engagement dans le Credo, c'est le serment du baptême. La vie entière est dominée par ce serment, car nous luttons sans cesse, chaque jour, contre Satan et les péchés; nous devons donc vivre cette alliance consentie avec Dieu notre Père. Pour prouver que c'est bien un serment qui a été établi, on peut piquer la Croix avec la statue de Jésus-Christ crucifié dans la cuvette contenant l'eau bénite pour le baptême. Si le baptisé est un adulte alors il tient luimême la Croix. Si le baptisé est un nouveau-né, ce sont ses parents ou son parrain qui tient la croix en prononçant le "Credo" [ou "serment"]. Il faut bien noter cependant que l'on n'invoque pas les ancêtres pendant le baptême, car Dieu est Amour et qu'il ne trahit jamais cet amour-là. Donc en retour, nous devons lui rendre cet amour. N'oublions jamais que si nous trahissons notre serment du baptême, alors nous redevenons esclaves de Satan.

Si le baptême concerne un adulte qui est prêt, donc on le fera communier dans le Pain et le Vin : il croit alors qu'il boit le sang du Christ. Le Baptême est donc vraiment une fraternisation par le sang ${ }^{35}$. 》

34. La citation suivante, bien qu'un peu longue, est essentielle à la compréhension du rituel inculturé.

35. «Velirano na vakirà : io fiekem-ponoana io velirano amin'ny batemy. $N y$ fiainana manontolo no voafehin'izany velirano izany, satria isan'andro isika no tsy maintsy miady amin' $i$ Satana sy ny fahotana, ary miaina araka ny fanekempihavanana natao tamin'i Zanahary Raintsika. Mba hanamarihana fa velirano tokoa no atao, dia aza atsatoka eo amin'ny finga misy ny rano fanaovana batemy, ny lakroa misy ny sarin' 'i Jesoa-kristy mifantsika : raha olon-dehibe no atao batemy, dia tànany ny lakroa : raha zazamena kosa, dia ny Ray aman-dReny niteraka na ny Mpiantoka no mitàna ny lakroa, sady manonona ny fiekem-pinoana. - Izao anefa no tsy maintsy fantatra tsara: tsy mba mitsitsika isika amin'ny batemy, satria fitiavana Andriamanitra, ary tsy mba mivadika amin'ny fitiavany izy. Noho izany, fitiavana no tsy maintsy havalintsika ny fitiavany. Tsy ho hadinontsika kosa, fa miverina amin'ny fanandevozan'I Satana, izay mivadika amin'ny Veliranon'ny bateminy. 
Le rituel proposé par le catéchisme n'est pas sans rappeler la gestuelle propre au rituel du vakirà. La croix dressée dans la cuvette d'eau bénite évoque en effet la sagaie piquée dans la cuvette lors du vakirà. La croix devient alors l'élément qui relie le candidat au baptême avec le Dieu chrétien, par l'intermédiaire de Jésus qui est sur la croix. Cependant, on peut noter déjà un déplacement spatial du sens de l'alliance. Si dans le vakirà l'alliance se fait entre « ego" de façon horizontale, dans le baptême elle se fait entre un homme et Dieu, de façon verticale. La présence du parrain ou des parents, qui tiennent le crucifix dans la cuvette pour le baptême d'un enfant, peut par ailleurs prêter à confusion et déplacer, dans les représentations bara, le sens de l'alliance chrétienne du baptême. Le crucifix peut aussi évoquer pour les Bara le hazomanga, pilier identitaire qui rassemble tous les membres d'une même famille. De plus, le hazomanga est aussi le lieu des tsipy rano, bénédictions diverses qui sont données par le lonaka, chef patriarche, dans diverses occasions. Or, les tsipy rano sont donnés avec de l'eau pure, rano velo, comme dans le cas du baptême, tandis que le rituel de fraternisation par le sang utilise un mélange d'eau, de terre, de suie et de $\operatorname{sel}^{36}$. Ce décalage pourrait laisser entendre aux Bara qu'en cas de trahison du baptême, la sanction pourrait être moindre.

Quoi qu'il en soit, cette proposition rituelle a été réalisée et mise en pratique le 23 avril 2000 à Ambatolahy, lors d'une cérémonie de baptême rassemblant trente-sept enfants. Présidée par le Père Colombi, la cérémonie s'est déroulée en présence des frères Ramaroson Alain Serge, Bototsariàny et Tiana, pendant le weekend de Pâques. Les baptêmes ont eu lieu dans l'église, devant l'autel. Les personnes âgées et les patriarches étaient rassemblés du côté ouest, tandis que la partie était occupée par les participants au baptême.

Raha olon-dehibe no atao batemy, ka vonona izy, dia omena Komonio Masina amin'ny endriki ny mofo sy ny divay: Mino na misotro ny Ran'I Kristy izy amin'izany, ka fato-dra marina tokoa ny batemy », ibid., p. 166-167.

36. Selon un conte expliquant l'origine de l'utilisation de ces éléments pour faire un vakirà, les ancêtres se seraient rendu compte que c'est la terre - et non l'eau qui, elle, permet d'unir - qui donne la sanction en cas de trahison. « Ňy mpifatidrà tsy mifampitata amin-drano, fa amiňn'ny botàny. Ňy mpifati-drà mifanoraky akata voho botàny laha misy marary fa nahafaty ňy taloha ňy nifampitata amiňn'ňy rano. ». 
Du point de vue de l'organisation spatiale, le baptême s'inscrit donc dès le départ en opposition avec le vakirà. Souvenons-nous que lors du rituel du vakirà, l'officiant - celui qui dirige la cérémonie - est à l'ouest. Dans l'église, le prêtre est au nord, derrière l'autel, tandis qu'à l'ouest sont rassemblés les patriarches. Dans le vakirà toujours, c'est l'assistance des témoins qui se trouve à l'est, tandis que dans l'église, ce sont les futurs baptisés, donc les candidats à l'alliance, qui s'y trouvent réunis. Dès le départ, on a donc une modification de l'espace symbolique rituel qui brouille les points de repère et offre une ouverture permettant de transformer ainsi le sens horizontal de l'alliance vakirà en une alliance verticale avec Dieu.

Il nous est impossible de continuer ici cette comparaison détaillée, qui mériterait que l'on se penche point par point sur la symbolique de chaque matériel utilisé (bougie, eau bénite, huile sainte, croix, sagaie, jonc, etc.) et de chaque geste rituel effectué (appel des baptisés, questions aux parents sur ce qu'ils attendent de cette alliance, présentation de l'enfant devant l'autel, aspersion d'eau, etc. $)^{37}$. Retenons cependant que l'analogie établie entre le vakirà et le baptême repose avant tout et exclusivement sur la notion d'alliance. Le fait que cette alliance soit théologale dans le cas du baptême, contrairement à ce que suppose un vakirà, est totalement occulté. Les différences sont escamotées au profit des correspondances, mises en avant dans le catéchisme. Il semblerait pourtant que la proposition rituelle du catéchisme n'ait pas rencontré l'enthousiasme escompté. Lors de nos différents séjours dans la région ${ }^{38}$, et lors des multiples entretiens que nous avons pu y réaliser, aucune mention ne nous a été faite du déroulement d'une autre cérémonie de ce type. À notre connaissance aucun baptêmevakirà n'a eu lieu pour des adultes, et il semble aujourd'hui que les représentants locaux éprouvent une certaine gêne à évoquer la cérémonie du 23 avril 2000. L'analogie catéchétique, si elle n'est plus ritualisée, est cependant encore bien présente dans les représentations et les discours.

37. Ce travail est une partie ethnographique importante de notre thèse de doctorat, dont la soutenance est prévue en décembre 2009.

38. Nous avons passé environ 25 mois en tout sur le terrain, entre 2001 et 2006 . 


\section{CE Qui RESTE du BAPTÊME-VAKIRÀ}

Si la ritualisation du baptême-vakirà a été abandonnée, le catéchisme quant à lui est toujours utilisé et fréquemment réédité en l'état. Pour les catéchistes souvent seuls en brousse, et n'ayant reçu qu'une formation minimaliste, ce livre est le seul soutien, la seule référence. L'idée d'un baptême-fraternisation est donc toujours véhiculée à travers eux et la catéchèse.

"C'est pour les parents qu'on fait la préparation du baptême, en expliquant pourquoi ils entrent dans le baptême. Ils vont devenir des enfants de Dieu, devenir frère de sang de Jésus et entrer dans la famille de Dieu. C'est-à-dire qu'ils ne feront qu'un en union avec Jésus, car Jésus est le fils de Dieu, et nous sommes adoptés aussi comme enfants de Dieu après le baptême. Mais nous les hommes, nous sommes des enfants nés et des enfants adoptés à la suite du baptême, c'est-à-dire mêmes héritiers que le Christ dans Dieu; c'est ça la base de la formation au baptême $\mathrm{e}^{39}$. »

L'analogie catéchétique permet à ce catéchiste de dire dans un premier temps que le baptisé devient le frère de sang de Jésus, ce qui fait de Jésus un alter ego, un membre de la parenté. Dans un deuxième temps, à travers le baptême et en devenant frère de sang de Jésus, le postulant est adopté par Dieu et devient son héritier, au même titre que Jésus et que les autres membres de sa famille. Ainsi, le baptême ouvre aux mêmes droits que l'adoption et offre une possibilité d'héritage que ne présente pas, en revanche, le vakirà. Or, lorsque l'on connaît l'écart socio-économique qui existe dans le Sud de Madagascar entre la population et les représentants religieux, devenir un héritier de l'Église par l'intermédiaire du baptême n'est pas négligeable et pourrait - au moins idéalement - devenir plus intéressant que le vakiră ${ }^{40}$.

39. "Amin'ny Ray aman-dReny izay miomana amin'ny batemy, dia hoe izay miditra amin'ny batemy, dia miditsa ho zanak'Andriamanitra, dia mpivakirà amin'ny kristy ary mpihavana amin'Andriamanitra. Izany hoe mpiray lova amin'I Kristy. Ka i Kristy zanak'Andriamanitra, dia isika zanak'Andriamanitra koa nantsangany tamin'ny batemy. Fa isika olombelona dia zanaka nateraka sy zanaka nantsangana taorinan'ny batemy noho izany mpiray lova miarak'amin'i kristy ao amin'Andriamanitra, izay no hampiofanana azy amin'ny batemy », Boto Tsilariva, catéchiste à Sahambano, interview réalisée à Ranotsara le 16 avril 2005.

40. Notons au passage que les Bara ont commencé à se convertir au christianisme seulement depuis une dizaine d'années et qu'actuellement, les convertis ne représentent qu'environ 3,5\% de la population, selon les statistiques de l'évêché. 
Par ailleurs, il semblerait que pour les Bara convertis, le baptême soit devenu un moyen d'établir de multiples vakirà.

« Si on parle du vakirà simple, c'est-à-dire que ce n'est pas un vakirà avec beaucoup de monde, mais un vakirà avec une seule personne. Mais le baptême te donne l'amitié avec tous ceux qui ont été baptisés. En tant que Bara, en tant que Malgache, je suis chrétien, il n'y a pas de différence [...], mais par contre je me suis lié amicalement avec le monde entier car j'ai eu le baptême. Les chrétiens sont tous liés dans le monde entier, mais le vakirà se limite uniquement à une liaison de parentétil .»

Le tour de force réussi par Mgr Jean-Guy Rakotondravahatra à travers l'invention de cette analogie catéchétique est d'avoir réussi à rendre le vakirà quasi-inutile pour les Bara en donnant au baptême une puissance supérieure à celle du pacte de sang.

« Mais si les deux personnes qui demandent à faire un vakirà sont déjà baptisées, je ne peux pas faire le vakirà, parce que Dieu a fini pour eux l'union par le baptême ${ }^{42}$. »

C'est là que réside toute l'ambiguité de l'inculturation ${ }^{43}$. Tout en annonçant vouloir protéger les cultures et les intégrer à l'Église par un mécanisme d'interculturation qui transformerait l'Évangile, le catholicisme semble au contraire vouloir entrer dans les rites locaux pour mieux les transformer de l'intérieur et les manipuler.

On constate néanmoins une constante augmentation du nombre de Bara convertis au catholicisme sans qu'il soit possible d'établir un rapport quelconque avec les remarques faites un peu plus haut.

41. "Io resaka vakirà farany io vakirà tsotra 'zany dia midika fa tsy vakirà amin'olo marobe fa vakirà amin'olo raiky, ka tsy vitan'ny hoe vakirà amin'olo raiky no havanao fa olo aby izay vita batemy. Ny maha bara no hoe ny maha kristianina, maha gasy tsy misy ny maha samihafa an 'izay [...], anefa dia mihavana amin'izao tontolo izao aho amin 'ny maha-kristianina vita batemy. Satria ny kristianina anie eran'izao tontolo izao, fa ny fatidrà da voafaritsa hoe fianakavia », interview de Rabernard, Ihosy, le 13 mai 2004.

42. «Ka raha ohatra anefa efa vita batemy ireo mangataky hanao vakirà, dia tsy afaky ny hanao an 'izay aho satria efa vitan'ny zanahary ny fampihavana ", Rabernard, op. cit.

43. Le cas de tentative d'inculturation que nous venons de présenter reste isolé. Pour d'autres prêtres malgaches, affectés parfois dans la même région, l'inculturation recouvre d'autres significations et doit donc se faire autrement qu'à travers la catéchèse. Voir par exemple Pietro Lupo (éd.), Mélanges. Ancêtres et Christ. Un siècle d'évangélisation dans le sud-ouest de Madagascar. 1897-1997, Fianarantsoa, Ambozontany, 1997 et collectif, Le Christianisme dans le sud de Madagascar, Fianarantsoa, Ambozontany, 1996. 
Les cultures sont soumises à une religion qui joue avec le potentiel syncrétique contenu dans chacune de ses rencontres avec les cultures. Le processus d'inculturation s'apparente alors à un processus syncrétique dirigé par les ouvriers religieux locaux; processus qui provoque lui-même un processus de réinterprétation dans la culture concernée. Le prêtre ou même l'évêque, souvent originaires d'une autre culture que celle de la région dans laquelle ils sont affectés, jonglent déjà entre leur propre héritage culturel et le christianisme. Chargés d'inculturer l'Évangile dans une autre culture, ils se livrent à une première réinterprétation de la culture locale afin de pouvoir y inclure le catholicisme. C'est à partir de cette réinterprétation que sera élaboré un plan pastoral et conçue l'inculturation qui donnera elle-même lieu à une réinterprétation de la part de la population réceptrice, et ainsi de suite. Ces processus syncrétiques en ricochet sont pour l'anthropologie l'occasion de revenir sur un concept qui touche à la complexité et à la pluralité culturelle. Néanmoins, le syncrétisme continue à être abordé de façon binaire et dualiste, et reste problématique ${ }^{44}$ non seulement dans l'ensemble des sciences humaines, mais aussi en missiologie, où il est souvent relégué à une simple phase inévitable, mais indispensable, du processus d'inculturation.

Quoi qu'il en soit, l'inculturation, telle qu'elle est pensée ici, ignore la complexité des représentations, la fluidité dans laquelle évoluent les individus au sein de leur culture que l'évêque catholique, auteur de cette inculturation catéchétique originale, considère semble-t-il comme un «bloc » culturel. Si le catholicisme allait véritablement jusqu'au bout de sa logique inculturative ${ }^{45}$ il devrait

44. C'est le travail théorique que nous nous proposons de faire dans notre thèse de doctorat, en ré-explorant les concepts de culture et de syncrétisme à travers le processus d'inculturation du christianisme. Sur la notion de syncrétisme, voir André Mary, Le Bricolage africain des héros chrétiens, Paris, Éditions du Cerf, 2000. Voir aussi pour les théories américaines Charles Stewart et Rosalind Shaw (éd.), Syncretism/Anti-Syncretism. The Politics of religious synthesis, European Association of Social Anthropologists, London and New York, Routledge, 1994; Jerald Gort [et al.] (éd.), Dialogue and Syncretism. An Interdisciplinary Approach. Currents of encounter. Studies on the contact between Christianity and other religions, Beliefs and Cultures. William B. Eerdmans Publishing Company Grand Rapids, Michigan. Éditions Rodopi, Amsterdam, 1989.

45. Pour une critique indienne de l'inculturation, voir Catherine ClementinOjha, «Indianisation et enracinement : les enjeux de l'inculturation de l'Église en Inde », Bulletin de l'EFEO, 80-1, 1993, p. 107-133. Michaël Amaladoss, A la 
sans doute envisager une multitude de processus inculturatifs, puisque chaque culture ne peut se lire et se vivre que dans la multiplicité des situations culturelles qu'elle crée. Poussée à l'extrême, l'inculturation devrait donc être conçue comme un processus individuel - et non plus social - de réinterprétation du christianisme propre à chaque être humain en fonction de ses propres identités culturelles ${ }^{46}$.

celine.rejasse@wanadoo.fr

rencontre des cultures. Comment conjuguer unité et pluralité dans les Églises?, Paris, Les Éditions de l'Atelier/Éditions ouvrières, 1997, 172 p.

46. Je remercie vivement $M$. Claude Prudhomme (université Louis-Lumière Lyon II) pour ses précieux conseils ainsi que Mme Hélène Bernier (Université de Cergy-Pontoise) pour sa lecture attentive. 